HID 44 (2017)

\title{
LA CASA DE RON. NOBLEZA Y MALFECHORES EN LA TIERRA DE CASTROPOL Y GRANDAS (SS. XV-XVI) ${ }^{1}$
}

\author{
THE RON LINEAGE. NOBILITY AND MALEFACTORS IN THE LANDS \\ OF CASTROPOL AND GRANDAS $\left(15^{\mathrm{TH}}-16^{\mathrm{TH}}\right.$ CENTURIES)
}

\author{
José ANTONIO ÁlVAREZ CASTRILlóN \\ Universidad de Oviedo \\ jcastrillon@uniovi.es
}

RESUMEN: El asesinato en 1564 de un sacerdote por un noble en la villa de Pesoz (Asturias), origen de una leyenda aún hoy conservada, llama la atención sobre la conducta recurrentemente violenta de un linaje preponderante en el occidente de Asturias - los Ron- que, si bien fue corriente hasta las primeras décadas del siglo XVI, resulta ya entonces anacrónica. Una exhaustiva labor de archivo permite trazar desde la baja Edad Media la trayectoria familiar y la configuración de su poder -socavado habitualmente al del clero-, contribuyendo a establecer un perfil de la pequeña nobleza propia del amplio territorio fronterizo asturgalaico a través de su linaje más representativo.

PALABRAS CLAVE: Linaje; noble sacrílego; nobleza; malfechores; Ron; Asturias medieval.

ABSTRACT: The murder in 1564 of a priest by a nobleman in the village of Pesoz in Asturias, the origin of a legend still remembered, is an example of the frequency of violent conduct in the Ron family, one of the most powerful families in western Asturias. This type of conduct was common up to the early $16^{\text {th }}$ century, when it began to wane. Intensive research has made it possible to reconstruct the family's rise to power and their relationship with the Church, and serves to draw a picture of the lesser nobility who lived on the Asturian-Galician border in the Middle Ages.

KEYWORDS: Lineage; sacrilegious nobleman; nobility; malefactors; Ron; Asturias in Middle Ages.

1. Abreviaturas utilizadas: AGS = Archivo General de Simancas; RGS $=$ Registro General del Sello; $\mathrm{AHA}=$ Archivo Histórico de Asturias; $\mathrm{AHN}=$ Archivo Histórico Nacional; ARChV = Archivo Real Chancillería de Valladolid; reed. = reedición; carp. = carpeta; doc. = documento. 


\section{UN NOBLE SACRÍLEGO Y SU INDULGENTE RECUERDO}

Según permite reconstruir la secuencia de pleitos a que dio lugar el suceso que ahora damos a conocer, el 26 de septiembre de 1564, en la villa de Pesoz, en el occidente de Asturias, Alonso Cuervo, cura de Grandas y Trabada, dos parroquias cercanas, comisario de la Inquisición y de familia hidalga asentada en la vecina comarca del Valledor, fue asesinado en la casa-torre de los Ron, linaje principal desde finales de la Edad Media en el amplio territorio fronterizo con Galicia.

Convocado con engaño por orden del caballero Álvaro Díez de Ron y Quirós, mayorazgo de la casa y con quien había tenido diferencias al punto de solicitar una carta de amparo real, acudió ese día para tratar un supuesto negocio y no volvió a salir con vida de la casa de los Ron. Su cadáver fue encontrado en la alejada comarca de Cecos, el pequeño señorío de Álvaro Díez en Ibias, enterrado a la vera de un río, con los pies atados y señales de haber sido ahogado con una cuerda. Le faltaban, según distintas declaraciones, ropas, capa, sombrero, espada y anillos, y cuarenta y tres ducados en monedas.

El fondo del cuadro es un amplio territorio de media montaña, de lomas suaves entre valles muy quebrados cortados por el río Navia y sus afluentes, que organiza en modestas parroquias una sociedad rural de base agroganadera, de férreo sometimiento clientelar al más poderoso como trasunto de una muy escasa presencia de la autoridad, representada por los alcaldes del obispo en la pequeña cabecera urbana local, Grandas, o en la principal y más alejada Castropol, radicada en la costa, y por otra parte siempre cuestionada por la pequeña nobleza local ${ }^{2}$. El momento histórico es, para lo que nos ocupa, el de un esfuerzo esencial y de un largo recorrido que impulsado por los Reyes Católicos habrá de cubrir todo el siglo XVI, para el fortalecimiento de las instituciones estatales, la reforma del clero, la pacificación de Asturias mediante el sometimiento de la revoltosa nobleza y la consolidación de los municipios ${ }^{3}$.

La imagen mundana que compone la descripción de un clérigo con un hijo públicamente reconocido, armado y vestido con ostentación, representa fielmente una situación aún corriente en tiempos de la Reforma que los obispos intentaban reconducir con desigual éxito 4 . Tampoco eran en modo alguno insólitos los abusos de un caballero acostumbrado en la tradición familiar al ejercicio impune de la violencia en su territorio de influencia por más que fuese señorío de la Iglesia de Oviedo ${ }^{5}$,

2. Ruiz de La Peña Solar 2005.

3. Sobre el conflictivo periodo en Asturias, además de Uría Ríu 2010, pueden ser de utilidad algunas aproximaciones parciales; así de Suárez Álvarez 1972; Villa González 1975 y González Calle 2007 (a).

4. El estado moral del Principado llevó a los jesuitas a considerarlo "unas Indias que tenemos en España". Aún al inicio del siglo XVIII un confesor dominico señalaba la escasa ortodoxia y virtud de los encargados parroquiales -"no se reza ni haze memoria por santo de alguno que cura párrocho lo fuesse"-. Santo Tomás y Pumarada 1714, p. 262.

5. La circunscripción jurisdiccional más extensa de la Asturias medieval, entre los ríos Eo y Navia, fue donada por Alfonso VI al obispado de Oviedo en 1144. La llamada Entrambasauguas, también fue conocida como Honor del Suarón, Tierra de entre Ove et Navia, Tierra de Entrerríos o Tierra de 
conducta que encaja de pleno en el perfil de los nobles malfechores ${ }^{6}$ habituales desde siglos atrás en Asturias y aún podría decirse en todo el norte peninsular como cabecillas de un bandolerismo tan corriente como para que una real provisión de los Reyes Católicos titule expresamente en 1493 impera la ley de los malfechores ${ }^{7}$.

En verdad se deberá recorrer un largo camino para que en 1594 el obispo Diego Aponte de Quiñones consigne sobre la diócesis ovetense en su visita ad limina que es

tierra pacifica, rara vez se producen violencias y reyertas [...] hasta hace sesenta o cien años estaba en vigor la venganza, así como la guerra entre los nobles arrastrando a la misma a la plebe. Esto ha desaparecido, al fortalecerse la autoridad de los reyes y sus ministros ${ }^{8}$.

Casi cinco siglos después del suceso aún queda recuerdo del mismo por la amplia cabecera montañosa del río Navia, en forma de una leyenda, la del Desterrado, que ofrece versiones diversas según la zona. Esa trascendencia, más allá del carácter sacrílego del homicidio, sin duda ha de ponerse en relación con sus poderosos protagonistas y, en un territorio caracterizado por la continuidad, con la estela de un poder que aún hoy perdura de modo legendario testimoniando cómo el cuerpo social asumió entonces un hecho tan aberrante 9 .

\section{LAS FUENTES Y LOS PROTAGONISTAS}

El acercamiento al contexto pasa obligadamente por el conocimiento de la trayectoria familiar, y este se ve lastrado tanto por la escasez de fuentes específi-

Ribadeo. A finales de la Edad Media su denominación más habitual es la de la Tierra de Castropol. A partir de los años ochenta del siglo XVI las necesidades económicas de Felipe II propiciaron que la Corona iniciase la desamortización de las jurisdicciones episcopales y su subasta, proceso que fue convirtiendo feligresías en municipios independientes. Cf. Pérez de Castro 1987, pp. 146-149; Álvarez Castrillón 2007, pp. 144-152; Fernández Suárez 2014, p. 688 y ss.

6. Durante la Baja Edad Media es una constante en todo el litoral cantábrico y Galicia la conflictividad de la nobleza. Cf. para el caso gallego García Oro 1981, Saavedra 1985, Lojo Piñeiro 1991 o Barros Guimarans 2008. Para Cantabria véase de Solórzano Telechea 2004 y 2005. Para Vizcaya Cf. Díaz de Durana 2004 y Dacosta 2003 y el caso guipuzcoano en Achón Insausti 1995. En Asturias, Ruiz de la Peña Solar 2005, amplia y revisa el clásico de Uría Ríu 2010 (reed.).

7. AGS., RGS. VIII-1498.

8. González Novalín 1986, p .50.

9. Una monografía local de finales del siglo XIX la resume así: "Pertenecía esta iglesia a la casa de La Uz, cuyos dueños, apellidados Miranda, eran señores de horca y cuchillo. Un día salieron á caza dejando ordenado al Sr. Cura que el domingo inmediato no celebrara misa hasta que ellos regresaran. Dícese que tenían este privilegio. No cumplió el sacerdote al pie de la letra el mandato; celebró la misa y cuando iba a terminar llegó uno de los señores y al verse desobedecido, montó en cólera y desde la puerta descargó su escopeta contra el ministro sagrado, que cayó muerto sobre las gradas del altar. Violada así la iglesia e indignados los fieles se gestionó entonces el traslado de la parroquia a Boal, y se consiguió hacia 1540. Así cuenta la tradición el origen de esta parroquia de Boal.” Acevedo y Huelves 1898 , pp. $30-31$. 
cas como por la carencia de estudios sobre el territorio en ese periodo ${ }^{10}$. No hubo en Asturias un Lope García de Salazar ni tampoco un Vasco de Aponte a cuyos repertorios de nobleza bajomedieval acudir ${ }^{11}$, ni se dispone de archivo familiar de ese tiempo y, así las cosas, la aproximación se limita a las posibilidades del rastreo en pleitos diversos, en muchas ocasiones tardíos, y algunas referencias indirectas que, finalmente, permiten perfilar a grandes rasgos un linaje, el de los Ron, cuyo protagonismo se revela esencial en el amplio extremo occidental de Asturias limitáneo con Galicia.

En el panorama que asoma a las fuentes diplomáticas de la baja Edad Media asturiana resulta una constante el protagonismo de un tipo social de gente de armas que la documentación identifica como caballeros o escuderos y cuya variada nómina permite a escala regional identificar un nutrido conjunto. Al socaire de la inestabilidad social y política del periodo su influencia fue creciente hasta resultar, en tanto que los perfiles van cristalizando y evidencian sus lazos familiares y su consolidación, un grupo homologable a la nobleza de menor rango. Con frecuencia son los mismos malfechores que perturbaron a las nacientes pueblas, a las jurisdicciones eclesiásticas o al propio realengo. Esa pequeña nobleza eclosiona en tiempo de los Trastámara aprovechando la subversión del orden nobiliario tradicional para reclamar el protagonismo que efectivamente ostentará en el final del medievo, y que será particularmente relevante en Galicia, sin duda la referencia más adecuada para contextualizar este estudio ${ }^{12}$.

Por lo que hace a la caracterización social del grupo estudiado, lo escaso y siempre escueto de la información manejada para las primeras generaciones lo complica. Entre los rasgos para una posible identificación del "hidalgo local" que se han venido manejando ${ }^{13}$, se ajustan particularmente en el caso que nos ocupa el que vivan de los suyo, sean señores que no ejercen señorío sobre vasallos y manifiesten dependencia vasallática con respecto a otros nobles. Descontada su autonomía económica, es claro el rango hidalgo de los Ron, por más que hasta bien entrado el siglo XVI, mediante matrimonio, no obtengan un señorío de vasa-

10. Por lo que respecta a la Asturias medieval, aún podemos suscribir la valoración historiográfica que realizaba hace unos años el profesor Ruiz de la Peña de esa "turbulenta nobleza inferior del país, sobre cuyas pautas de comportamiento, vínculos familiares, patrimonios y peso social, económico y político en la vida asturiana de la época sabemos todavía muy poco" Ruiz de la Peña Solar 2002, p. 9. La carencia de estudios es más acuciante en el caso del occidente de Asturias, muy malparado salvo en el periodo castreño en la atención de la historiografía regional con respecto al centro de la región. Pese a la abundancia de fuentes, del amplio espacio occidental asturiano del Navia-Eo tan sólo se han publicado dos tesis doctorales (Álvarez Castrillón, 2007 y Suárez Fernández, 2014) ambas interesadas en la organización social del espacio medieval.

11. Ofrece un detallado panorama de ese tipo de fuentes genealógicas Pardo de Guevara y Valdés 2012, pp. 19-31. Con carácter general tomamos como referencia el estudio de Calleja Puerta 2010.

12. García Oro 1987, p. 255. Lo ha estudiado con detalle en el entorno gallego Pardo de Guevara y Valdés 2012. Como afirma, la reestructuración de la pirámide nobiliaria en el noroeste aún habría de dejar ocasión en la segunda mitad del siglo XV para "un gran número de estirpes de extracción diversa, muchas nuevas y algunas no tanto, la mayor parte de las cuales se habían enriquecido a la sombra de los monasterios y cabildos catedralicios" p. 69.

13. Díaz de Durana 2004, p. 81. 
llos, y asimismo es evidente su incardinación en la compleja malla de los Osorio y su subordinación a estos.

Como se verá, las escasas referencias documentales permiten distinguir cierta evolución desde la categoría de los primeros Ron, que parece muy cercana al topónimo que les da nombre, a la del grupo familiar que en el siglo XV ha dejado ya muy lejos la aldea samartiega de su nombre como solar de referencia para ubicarse en la villa de Pesoz o desplegar su influencia en la marina asturgalaica ${ }^{14}$. En la pirámide nobiliaria que hace unos años describía para ese tiempo Díaz de Durana $^{15}$, que puede considerarse liderada por los ricos hombres o su equivalente, con un segundo escalón para caballeros de proyección regional o comarcal, y un amplio soporte de hidalgos y escuderos sin señorío, los Ron habrían partido de este último escalón para promocionar al término de esa centuria hasta el de nobles con proyección regional.

Resulta conveniente asimismo una reflexión sobre el concepto de linaje, controvertido en ocasiones y recurrente siempre en estos casos. Identificado con la clase dominante, en el ámbito oriental de la cornisa cantábrica un estudio específico establecía hace ya unos años tres acepciones, sumando a las dos clásicas, la agnaticia -en el sentido de vínculo entre nieto y abuelo- y otra más amplia que refiere a todos los descendientes de un ancestro, una tercera que superaba el estricto parentesco para considerar el clientelismo, las relaciones económicas y un marco amplio de sociabilidad ${ }^{16}$. Asimismo, la inclusión de parentescos artificiales ha permitido su identificación con el bando, y señalar cierta evolución en tanto que el objetivo se desplace, en paralelo a la generalización de los vínculos de mayorazgo, del grupo amplio a la prosperidad de un determinado solar, lo que paulatinamente introduce el más individualizador concepto de casa desplazando al de linaje ${ }^{17}$.

Ese concepto de casa es el usual en Galicia, como bien se advierte en las crónicas de Vasco de Aponte ${ }^{18}$, y también en el occidente asturiano.

Para la utilidad de nuestro acercamiento, dado que abarca varias generaciones, consideramos apropiado el criterio más estricto, el agnaticio, para concretar el protagonismo de la rama familiar en la que se sostuvo la primogenitura -vector de referencia en este caso- hasta el momento señalado del pleito, cuando aparece bien definida la Casa de Ron de Pesoz.

14. El hecho de que sus propiedades conocidas en la propia aldea de Ron no sean muy relevantes refuerza cabalmente esa conjetura de su emergencia desde la condición de escuderos.

15. Cf. Díaz de Durana 2004, p. 44.

16. Cf. Dacosta 2003, p. 22. En el caso de Cantabria, las posibilidades de las fuentes limitan a consideraciones sobre los testamentos, que no obstante apuntan cierta correspondencia con lo anterior: primero restringido a lazos de sangre y a no más de tres generaciones, se va extendiendo a la red clientelar hasta configurar una más amplia. Cf. Solórzano Telechea, 2002.

17. Achón Insausti 1995, p. 66. Una síntesis en Díaz de Durana 2004, pp. 125-126.

18. Señala cómo lo prefiere al término "linaje", García Oro 1987, p. 271. 


\section{ANTECEDENTES De LA CASA DE Ron: LA ESTELA DE LOS OsORIO}

En consonancia con lo ya señalado para el conjunto del reino, en el cuarto más occidental de Asturias que conformó la jurisdicción episcopal de la Tierra de Ribadeo, habían venido cobrando protagonismo desde el siglo XIV algunos personajes que los textos refieren como escuderos, o también a veces como fidalgos, que resultan desconocidos en la documentación anterior y de cuya extracción comarcal suele dar cuenta el topónimo que los apellida. Cuando en 1368 el caballero leonés Alvar Pérez Osorio consiga del obispo don Sancho las encomiendas de toda esa amplia obispalía - la ya conocida como Tierra de Ribadeo y la Tierra u Honor de Grandas- la mayoría se integran en su amplia clientela, y en las actas que lo testimonian resuenan ya muchos de los apellidos que habrán de conformar el panorama nobiliario comarcal de época moderna.

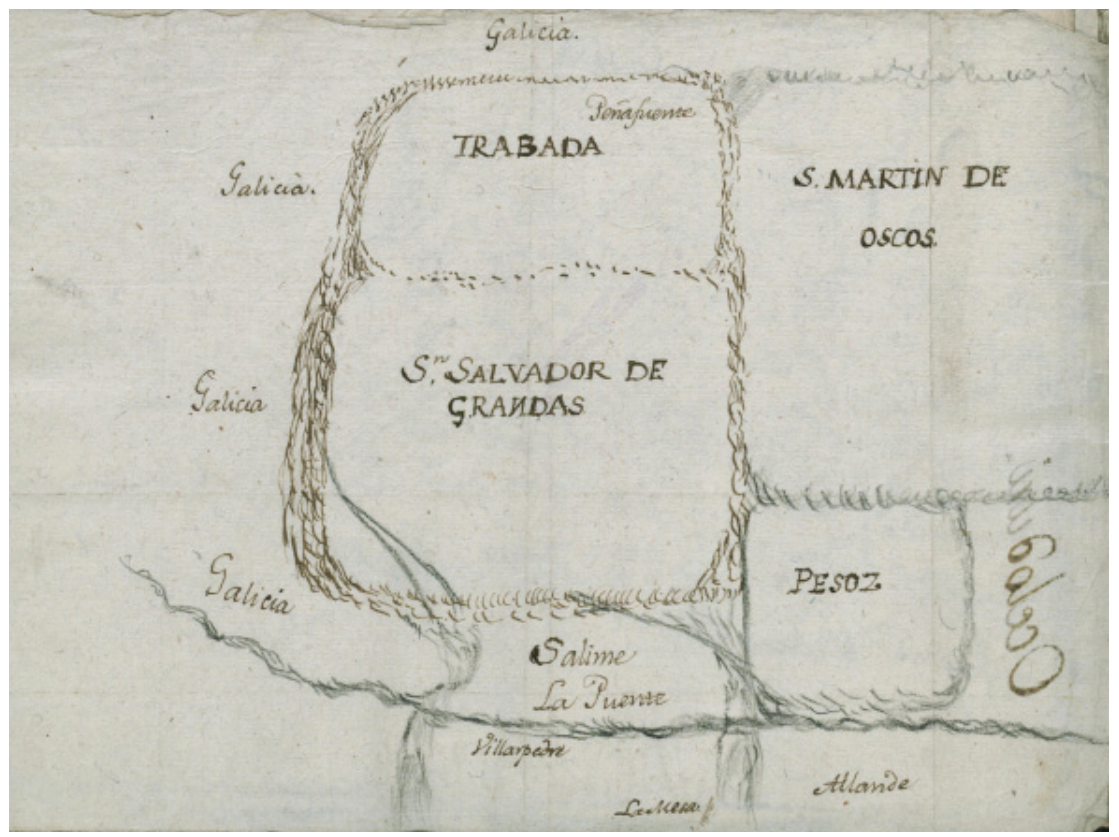

Fig. 1: Bosquejo de la división administrativa del Honor de Grandas a finales del siglo XVIII. Real Academia de la Historia. Papeles de Martínez Marina para el diccionario Geográfico Histórico; legajo 6036.

De la estirpe de los Ron ya ofrecen noticia mediado el siglo XIII diversas comparecencias documentales de Pedro López de Ron entre los notables del territorio que acompañan al tenente de la jurisdicción ${ }^{19}$, denotando una probable condición

19. Pedro López de Ron comparece entre varios notables testificando diversos negocios del tenente episcopal Gonzalo Menéndez en 1252 y nuevamente en 1265. Álvarez Castrillón 2011, docs. $117 / 118$ y doc. 146 respectivamente. 
de hombre de armas. Sin embargo, la siguiente referencia habrá de esperar un siglo, y se produce ya en la clientela de los Osorio, en cuya estela medran desde los primeros tiempos de su encomienda y donde cabe rastrear el origen de su preeminencia.

Así podemos saber en 1381 de Gonzalo Fernández de Ron prestando homenaje al obispo de Oviedo con otros caballeros del territorio vasallos del comendero ${ }^{20}$. Y en 1411 de un pariente suyo, Diego Sánchez de Ron, mostrándose expresamente activo en un perfil de caballero malfechor que nos servirá de antecedente, cuando realiza una donación al monasterio de Santa María de Villanueva de Oscos por enmenda das casas que queyméy e derribéy enno dito monesterio ${ }^{21}$.

Puede suponerse cabalmente que este último sea el padre del Álvaro Díaz de Ron que presenta Vasco de Aponte al servicio de Pedro Álvarez Osorio y cuya muerte sitúa en un enfrentamiento con los partidarios del arzobispo de Santiago en torno a $1461^{22}$. En cualquier caso, a partir de él las fuentes permiten trazar con seguridad su descendencia hasta quien nos ocupa.

Los Osorio resultaron definitivamente encumbrados cuando Juan II concede en 1445 el título de conde de Trastámara a Pedro Álvarez Osorio, quien adquiere en 1457 las pueblas de Burón y Navia de Suarna ${ }^{23}$. En 1461 hereda el título el primogénito, Álvaro Pérez Osorio, quien tres años después traspasa el señorío de Burón, Navia de Suarna y Val de Lourenzá -la orla nororiental lucense- a su hermano, Pedro Osorio de Villalobos, pronto destacado capitán irmandiño y segundo marido de Urraca de Moscoso, la heredera del condado de Altamira. De ese modo pasaron luego a ese título y su descendencia-Rodrigo Osorio de Moscoso- los derechos sobre Burón y el alto Navia, simbolizados en sendas fortalezas que señoreaban las respectivas pueblas ${ }^{24}$. A su vez, el vasallaje de los Osorio en la zona serviría a la casa ya hermana, y así muchos partidarios suyos en el occidente de Asturias resultaron vinculados a la rama enlazada en la casa de Altamira ${ }^{25}$.

Por su parte Álvaro Pérez Osorio, II conde de Trastámara, recibe en 1465 el título de marqués de Astorga evidenciándose ya como uno de los mayores poderes

20. Rodríguez Díaz 1995, doc. nº 25. La encomienda de los Osorio, por más que no tengan su residencia en él, proyecta la influencia del linaje en el territorio que nos ocupa durante toda la baja Edad Media y aún mediado el siglo XVI. Vid. Al respecto Álvarez Castrillón 2007 p. 288-302.

21. Álvarez Castrillón 2001, pp. 213-214. En palabras de García Oro 1987, p. 21, crímenes y penitencias son el binomio definidor de la atmósfera social que se respira en la Galicia medieval.

22. Vasco de Aponte 1986, pp.174 y 175.

23. Martín Fuertes 1987 y 1988. También Rubio Pérez, 2002. Juan II las había donado en 1448 a Alonso Pérez de Vivero, contador real.

24. El señorío sobre ambas pueblas no dejará de ser discutido por los vecinos, que alegaban ser de realengo. Urraca pleitará en repetidas ocasiones hasta lograr el reconocimiento de su señorío. Cf. de García Oro y Portela Silva 2003, pp. 36-37.

25. En Asturias dos pequeños señoríos, el de San Tirso de Abres, que se repartía con el monasterio de Santa María de Meira, y el coto de Figueras pasarán a Lope Moscoso, conde de Altamira, en 1537, por venta del marqués de Astorga, Pedro Alvarez Osorio. 
en el noroeste, a la altura de otras casas condales como Lemos, Ribadeo, Camiña, Monterrey o Salinas ${ }^{26}$.

Por entonces estalló en Galicia la revuelta de los irmandiños, a quienes apoyarán decididamente los Osorio $^{27}$, y en un pasaje de la narración de Vasco de Aponte, encontramos un elocuente cuadro en el que coinciden

don Pedro Osorio, hijo del conde viejo de Trastámara, y hermano del marqués viejo de Astorga señor de la casa de Villalobos, el qual don Pedro estaba por capitán de la comunidad que tenían de diez mil hombres arriba, y entre ellos muchos fidalgos, que eran del estremo de las Asturias, y otros gallegos, y otros venian con él de los de Navia y Burón ${ }^{28}$.

En este último grupo mencionado, en el de los fidalgos del occidente de la diócesis de Oviedo, se sitúa el linaje protagonista de este estudio ${ }^{29}$.

Sofocada la revuelta, en la década siguiente, al socaire de la guerra de los Reyes Católicos contra Portugal por la sucesión de la Corona de Castilla, emerge en la Galicia oriental la figura del mariscal Pedro Pardo de Cela. Significado al servicio del conde de Lemos contra los irmandiños ${ }^{30}$, medró después como comendero del obispado de Mondoñedo, hasta resultar, en palabras de Vasco de Aponte, "gran señor", para acabar enfrentado al cabildo y desafiando el mandato real. En su fortaleza de A Frouxeira resistió desde 1481 a 1483 el asedio de las tropas reales hasta que la traición de algunos servidores la rindió y fue apresado con su yerno Pedro de Bolaño y con Pedro de Miranda ${ }^{31}$. La crónica de Diego de Varela relata que fueron prendidos con ellos, entre otros, un fijo del mariscal e otro de Pedro de Miranda, los quales todos [...] fueron degollados, los quales eran hombres de estado e linaje $e^{32}$.

26. Ladero Quesada 1996, señala estas como las más destacadas de una Galicia fuertemente señorializada, al tiempo que subraya la inexistencia de casas parangonables en la franja litoral cantábrica.

27. El compromiso de los Osorio astorganos con el levantamiento popular se explica por el interés de la monarquía en debilitar la excesiva influencia de las principales casas nobles gallegas. Barros Guimerans 1988, califica las revueltas irmandiñas de verdadera revolución social que "marcó la transición de la Galicia de las fortalezas y de la nobleza feudal (s. XV) a la Galicia de los pazos y de la hidalguía (siglo XVI)". El más modesto equivalente asturiano de las alianzas concejiles frente a la nobleza en Ruiz de la Peña Solar 2005.

28. Vasco de Aponte 1986, p. 224.

29. La archidiócesis de Oviedo, que excedía los límites asturianos, comprendía diversas parroquias lucenses, encuadradas en los arciprestazgos de Castiel de Navia y Burón. En 1954, en una reorganización de límites eclesiásticos, resultaron incorporadas al obispado de Lugo.

30. Quedó para la historia su propuesta de "llenar los carballos de vasallos" como represalia sobre la hermandad, rechazada por el conde con el argumento de que "no comería de los carballos".

31. Un acercamiento al ascenso de un Pardo de Cela utilizado por la monarquía en Viveiro y su posterior caída en desgracia en Rubio Martínez 2012. En 1474 Pardo de Cela prestó juramento de fidelidad a la reina Isabel como justicia y gobernador de la villa de Viveiro. Ese mismo año se intitula ya como mariscal, según Meilán García 2006, p. 224. Transcribe y estudia el testamento de Pardo de Cela, Pardo de Guevara y Valdés 2013.

32. Crónica de los Reyes Católicos, Cap. XXXV, 103-104, recogido por Pardo de Guevara y Valdés 2006 p. 48. El episodio pasó pronto a la leyenda popular que con el tiempo alimentaría fabulaciones nacionalistas como el lance más recurrido de lo que llegó a llamarse "doma y castración del Reino de 
En este ilustrativo episodio acerca del encumbramiento de los hombres de armas con abuso de las jurisdicciones eclesiásticas, y en la estela de ese personaje de leyenda aparece netamente otro linaje, el de Miranda ${ }^{33}$, con el que resultará enlazado el de los Ron y que aún resuena en algunas variantes de la leyenda que nos ocupaba al inicio ${ }^{34}$.

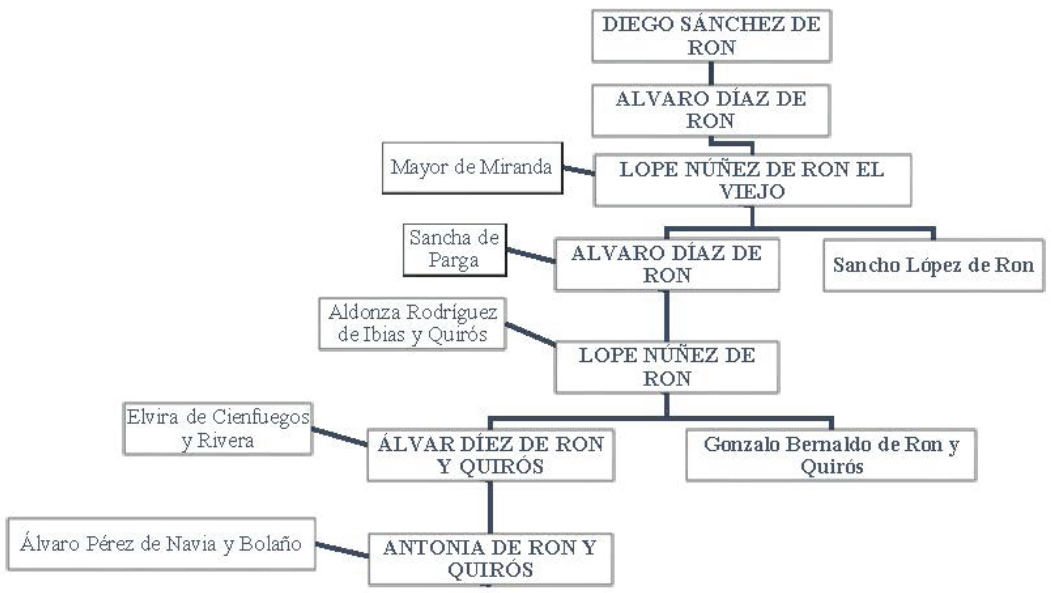

Fig. 2: Árbol genealógico de los Ron, ss. XV-XVI.

Poseedor de la fortaleza de Boulloso, el mando de setecientos hombres que se le atribuye sin duda convertía a Pedro de Miranda en referencia militar esencial en la orilla gallega del $\mathrm{Eo}^{35}$. Antiguo vasallo de la casa de Andrade, los matrimonios de sus dos hijas -Mayor de Miranda con Lope Núñez de Ron y María de Bolaño con Álvaro González de Rivadeneira- reforzaron su posición al punto de permi-

Galicia”. Castelao interpretó así la referencia de Jerónimo Zurita y Castro en sus Anales de la Corona de Aragón: "Galicia se redujo a las leyes de la justicia, a donde el rey puso audiencias. En aquel tiempo se comenzó a domar aquella tierra de Galicia, porque no sólo los señores y caballeros della pero todas las gentes de aquella nación eran unos contra otros muy arriscados y guerreros". Cf. al respecto, Pardo de Guevara y Valdés 2012, p. 475-512. Un análisis del largo proceso de mitificación desde las crónicas y la tradición popular en Meilán García 2006.

33. El territorio de Miranda ocupaba las márgenes del curso medio del Eo, parte de los actuales municipios de A Fonsagrada, A Pontenova, Trabada y Ribadeo, y por el lado asturiano Taramundi. En la Edad Media, según la nómina parroquial de 1385, el arciprestazgo de Miranda, perteneciente a la diócesis de Oviedo, comprendía las parroquias de San Martino de Taramundi, Santiago de Avres, San Salvador de Villacán, Santa María de Genestosa, San Salvador de Santisso, San Juliano de Villabona y Santiago de Villaodriz. Cf. ACO, Libro Becerro, f. $379 \mathrm{v}^{\circ}-380 \mathrm{r}^{\circ}$. El castillo de Pedro de Miranda era el de Boulloso, en la parroquia de Santa María de Conforto (A Pontenova).

34. Así en la versión que corre en el territorio de Boal, en el entorno del lugar de Prelo, y que se reproduce al inicio. Cf. supra.

35. Lence Santar y Guitián 1930, pp. 76, 77, recogido por González Paz 2004. Respecto al contingente Vasco de Aponte indica "Pedro de Miranda no baxaba de mandar seteçientos hombres; los que eran vassallos no podían bajar de çiento." Vasco de Aponte 1986, pp. 132-133. 
tirle independizarse y seguir al mariscal Pardo de Cela, como afirma Vasco de Aponte porque tenía buena renta, y buenos dos yernos ${ }^{36}$.

Y es aquí, al inicio de la década de 1480, junto a su influyente suegro Pedro de Miranda $^{37}$, cuando este Lope Núñez de Ron al que llamaremos "el viejo" consta ya netamente instituido como caballero, cabeza del linaje más inquieto y de mayor relevancia en esas décadas de la Tierra de Castropol y aupado, como veremos, a un protagonismo esencial por toda la confluencia asturgalaica.

\section{LA LEY DE LOS MALFECHORES}

En la última década del siglo XV menudean las disposiciones de los monarcas alusivas a la tierra de Castropol, todas redundando en la permanente conflictividad y en señalar como protagonistas a algunos caballeros. La exacción de impuestos abusiva y sin derecho, habitual lamento - en la dicha tierra se fazen muchos dapnos e repartimientos syn nuestra liçençia e mando, e que cada hun anno fazen repartir e reparten en los dichos conçejos de la dicha tierra más de sesenta mille maravedís syn aver cabsa dello ni aver necesydad, acusa expresamente una real provisión $^{38}$ - se muestra como una de las vías esenciales de financiación de un grupo de hidalgos cuya base patrimonial estaba muy mermada desde tiempo atrás como para sostener un séquito de hombres armados en número suficiente para hacerse merecer ${ }^{39}$.

Otras veces, muchas, aparece el robo, y casi siempre por medio venganzas y odios personales. Por el tiempo de la toma de Granada la situación se evidencia especialmente tensa, y debió de serlo en los diversos reinos. En la tierra de Castropol las reales provisiones detallan a la pequeña nobleza y elocuentemente refieren su influencia clientelar al tiempo que denuncian su actuación como cabecillas de un bandolerismo habitual:

çiertos onbres principales a los quales dizen que se allegan toda la más de la gente que viven en la tierra de Castropol que biben en la dicha tierra, Lope Núñez de Raon, e Alvar Díaz su fijo, e Alvar Pérez de Navia e Alonso Pérez de Aguyar su fijo e Lope Méndez de Donlebún e Lope Méndez su nieto e Arias Núñez de Presno e otros de aquella calidad. [...] se acompañan de muchos ombres malos, asy roba-

36. Ibidem. Pedro de Miranda y su mujer Inés yacen enterrados en el monasterio de Santa María de Meira. En el mismo sepulcro fue sepultada su hija María de Bolaño.

37. A la muerte de Pedro de Miranda la casa de Miranda queda ya en la línea de los Ribadeneira. Un acercamiento al linaje de los Ribanedeira en ese momento histórico en García Oro y Portela Silva, 2002 .

38. Cf. infra doc. de 23 de agosto de 1493. El fenómeno es común a la cornisa cantábrica. En el País Vasco se ha definido como principal expediente de una "ofensiva señorial” de prolongada cronología, que tiene su origen en las mercedes enriqueñas y se manifiesta reiteradamente en forma de aumentos arbitrarios de las tasas. Cf. Díaz de Durana 2004, pp. 174 y ss.

39. Cabe recordar aquí los setecientos del contingente de Pedro de Miranda de los que daba cuenta Vasco de Aponte en los conflictos irmandiños. Cf. supra. 
dores como matadores e personas que han fecho otros delitos feos, e que quando quier que las justiçias los van a prender que los defienden e que algunas vezes sobre prender las tales personas han acuchillado la justiçia ${ }^{40}$.

Similares disposiciones de los reyes para otros territorios indican que el comportamiento de la pequeña nobleza acogiendo "homezidas, matadores, sentençiados y encartados" fue común.

En ese mismo año 1493 una carta de los Reyes Católicos deja ver que es corriente en todo el Principado que caballeros, escuderos y parientes mayores campeen por sus comarcas con varios peones manteniéndose a costa del vecindario, impongan jueces y alcaldes en los realengos y extorsionen a las obispalías con el arriendo de los impuestos ${ }^{41}$.

En el País Vasco asoman con frecuencia en los textos, vinculados al linaje, huidos de la justicia que buscan refugio en las torres señoriales participando en las escaramuzas y batallas junto a otros miembros de la parentela ${ }^{42}$. La gravedad del problema es tal que en las cortes de Toledo de 1480 los reyes habían dispuesto la prohibición del mantenimiento de esas huestes particulares, aunque con poca fortuna pues el problema seguirá mostrándose endémico. En Cantabria se prolongó hasta al primer tercio del XVI ${ }^{43}$. En Galicia el fenómeno muestra similar intensidad, particularmente en el territorio de Mondoñedo, donde perduran las banderías muy avanzado el reinado de los Austrias, la violencia es habitual y aún mediado el siglo XVI la prohibición de portar lanzas y ballestas -ya de 1515- es contestada invocando la costumbre y la necesidad de protegerse de los bandidos ${ }^{44}$. Sólo a finales de la centuria puede decirse que la toga se ha impuesto sobre la espada en el arbitraje de la vida cotidiana.

Pero, al acabar el siglo XV, con frecuencia y por encima de consideraciones morales o legales, las continuas necesidades bélicas reforzaban la figura de la gente de armas hasta hacerlos imprescindibles. En el siempre complejo procedimiento de levantar un ejército los escrúpulos iban cediendo ante las dificultades y la guerra, principal fuente de gloria, se revela como un trance que expía cualquier culpa. La propia monarquía ofrece ejemplo de ese proceder, y elocuente muestra encontramos para este caso en el perdón que concede en 1490 a quien luego vemos liderar las algaradas, Lope Núñez de Ron -el viejo-, sobre determinada condena por homicidio. La figura legal que lo ampara es el "perdón de homiciano", un indulto a cambio de un servicio de cuatro meses en la guerra y que fue profusamente utilizado en las levas. Que el condenado pueda cumplir a través de un tercero a sueldo traslada la evidencia de la práctica impunidad para los hidalgos con recursos:

40. AGS., RGS., leg. 149308, 178.

41. Da noticia, trasladándola de Ciriaco Miguel Vigil, Uría Riu, 2010, pp. 302-303.

42. Cf. Díaz de Durana 2004, pp. 128 y ss.

43. Solórzano Telechea 2005.

44. Cf. el amplio estudio de Saavedra 1985, p. 45. 
[...] E agora por parte de Lope Núñez de Ron, vezyno del conçejo de Grandas, que es en las Quatro Sacadas, nos fue fecha relaçión que él enbió a servir por omiziano en la dicha guerra el dicho año de ochenta e nueve a Pedro de Guevara, alcalde que fue de la fortaleza de Rebolledo, el qual nos syrvió en ella todo el tienpo de los dichos quatro meses a su costa e misión [...] por ende que nos suplicava e pedia por merçed que, pues avía fecho el dicho serviçio en la manera que dicha es y el dicho nuestro corregidor fallesçió antes de le dar la dicha carta de perdón, le mandásemos dar nuestra carta por que pudiese gozar del dicho perdón, como lo fyzieron los otros omizianos del dicho Prinçipado e Quatro Sacadas que nos vinieron a servir en la dicha guerra del dicho año, o le proveyésemos çerca dello, commo la nuestra merçed fuere; e nos tuvímoslo por bien ${ }^{45}$.

Encumbrados en el contexto del casi constante estado de guerra que venimos describiendo, en el que se enlazan conflictos sucesorios con revueltas irmandiñas, banderías y las guerras de frontera en Granada y Portugal, algunos linajes perseveran en ese modo de hacer que es también un arma política con buenos réditos y de mecánica sencilla: a cambio de la paz arrancan concesiones. La decidida política de los Reyes Católicos para reconducir la situación necesitó tiempo y desplegarse en diversos ámbitos: apaciguamiento de la nobleza y castigo ejemplar de los rebeldes, abatimiento de las torres y fortalezas que les servían de amparo, reforma de las órdenes monásticas para situar al frente a abades sin connivencias con las élites locales, implantación de los corregidores y creación de la Real Audiencia de Galicia.

El hito inaugural de esa ofensiva monárquica en Galicia es el envío en 1480 de Fernando de Acuña como gobernador al mando de 300 lanzas que le permiten enfrentar a la nobleza. Su ya referido escarmiento sobre el mariscal Pardo de Cela anticipa el triunfo definitivo y el sometimiento de los nobles ${ }^{46}$.

En el Principado esa política se inicia con el nombramiento desde 1475 de corregidores, representantes regios con poderes judiciales y de gobierno ${ }^{47}$. Entre sus principales tareas estaba la de rescatar para la Corona las amplias prerrogativas que detentaban los Quiñones, titulares del condado de Luna. Tras un pleito de siete años, los reyes acaban logrando en 1490 la renuncia del conde de Luna a todos los derechos en Asturias, y corregidores, concejos y la mitra irán tomando las riendas poco a poco, en competencia ahora con otros linajes emergentes.

Por ese tiempo ya había crecido en la región el protagonismo de los Quirós y los Miranda, dos parentelas de la Asturias central de rivalidad irreconciliable que

45. AGS., RGS. II-1490-58.

46. Es bien elocuente de la situación la memoria que un siglo después recogerá el jesuita Luis Alfonso de Carvallo resaltando que Acuña, con gente de guerra y el letrado García López de Chinchilla, sacaron aquel reyno -Galicia- de la opresión y tiranía de los que lo tenían fatigado, principalmente de la severidad de Don Pedro de Miranda, y del mariscal don Pedro Pardo, cavalleros muy poderosos en Galicia, en las partes que confinan con Asturias, los quales fueron ajusticiados, aunque ofrecian gran cantidad de oro y plata en rescate de sus vidas. De Carvallo 1695, edición de Silverio Cañada, 1988 , p. 445.

47. Cf. Cuartas Rivero 1975. 
en su lucha por el predominio provocan una verdadera anarquía durante la segunda mitad del siglo ${ }^{48}$.

En ese contexto hemos de situar la orden dada por los Reyes Católicos en 1483 para derrocar en Asturias torres y casas fuertes, y otra averiguación ordenada diez años después sobre los caballeros, escuderos y parientes mayores del dicho Principado sin liçencia e facultad de los reyes pasados que habían levantado fortalezas y torres, testimoniando en la región el empeño común a todos sus reinos de derribar las sedes de los nobles díscolos y malfechores pero también un cierto aire de desafío y relativa impunidad ${ }^{49}$. Al cabo resultará una de las medidas más efectivas.

Con todo, la Tierra de Castropol parece escenario aparte, ajena al oriente del Navia, y de continuo transmite la impresión de mirarse en el espejo de Galicia, sin duda porque allí radican tradicionalmente los mayores intereses de los nobles, como ya se ha visto. Cuando, en lo peor del conflicto con los Quiñones, los reyes envían al Principado al corregidor Luis Mejía dotado de poderes especiales ${ }^{50}$, lo hacen hasta el agua del Navia, lo que bien puede interpretarse como indicio de que el territorio occidental merecía consideración singular y constituía otra realidad. Incluso en ocasiones los oficiales fueron enviados desde Galicia; así ocurre cuando en agosto de 1493 los reyes encargan a su corregidor en Mondoñedo una averiguación sobre los desmanes de ciertos caballeros encabezados por Lope Núñez de Ron y su hijo Alvar Díaz que denuncia de forma bien elocuente Rodrigo García de la Rúa, tenente episcopal y alcaide en Castropol:

algunas veces han retado e matado a las justiçias que los van a prender e que les han tomado los malfechores por fuerça de manera que con el poder que los susodichos tienen diz que se recojen a ellos los malfechores que ay en la tierra y que ellos los reçebtan e defienden e que se acompañan dellos de manera que la justiçia no se puede esetuar en ellos e otros que biven bien ${ }^{51}$.

48. Calleja Puerta 2005, pp. 286-287. Pese al apelativo compartido de Miranda no tienen relación aún el linaje gallego y éste asturiano. Sí la tendrán sus descendientes a lo largo del siglo XVI por enlaces matrimoniales. De resultas del enfrentamiento entre los Quirós y los Miranda se llega al asesinato de diversos oficiales regios. AGS., RGS, LEG, 147909,110. Cf. infra. Véase al respecto, de González Calle, además de 2007a, ya citada, 2007 b.

49. AGS., RGS., LEG, 149309, 36.

50. Cuartas Rivero 1975, p. 265.

51. AGS., RGS. VIII-1498-114. Poco después el propio alcaide Rodrigo de la Rúa solicitaría reiteradamente amparo real ante ciertas heridas y las amenazas de Arias Núñez de Presno, Lope Méndez "el mozo", y otros. Su osadía había llegado al punto de acuchillar al alcaide en una audiencia pública. El castigo se encarga al gobernador del Reino de Galicia, Diego López de Haro, y a Fernando de Vega, corregidor del Principado y Cuatro Sacadas de Asturias de Oviedo, orden que meses después deberá ser reiterada lo que denota una habitual impunidad. Respectivamente en AGS., RGS., Leg, 149510,198 y, en mayo de 1496, Leg, 149605,107. Los seguros de Gonzalo de la Rúa en AGS., RGS., en octubre de 1495, Leg, 149510, 213 y, en mayo de 1496, Leg, 149605,109. Al acabar el siglo, el cuadro que venimos describiendo se remata con una formidable asonada: en febrero de 1500 los reyes deben socorrer de nuevo con su alguacil a la obispalía de Castropol pues "[...] unas personas con gran armada habían ido a la villa de Castropol que es del obispado de Oviedo e le habían combatido con lombardas e tiros de pólvora [...] e diz que sobrello falló culpables a muchas personas vezinos del dicho Principado e de las quatro villas e lugares del dicho reino de Galicia.” AGS., RGS., Leg. 150002, 48 y 115. 
Como puede verse, Lope Núñez de Ron "el viejo", hombre de su tiempo, se muestra digno continuador de Pardo de Cela e, imitando su comportamiento, encabeza la ofensiva señorial en el territorio quebrantando de continuo la autoridad de la justicia al punto de que el obispo debe solicitar ayuda a los monarcas.

Las obispalías y los monasterios aún eran, por débiles, blanco preferido de extorsión, y lo seguirán siendo de los Ron durante generaciones. Así, en 1499 es el segundo hijo de Lope Núñez "el viejo", Sancho López de Ron, quien obliga al abad de Villanueva de Oscos a solicitar de los reyes un seguro de tenor bien elocuente:

\section{[...] se teme e reçela que por hodio e henemistad e malquerençia que contra él han e tyenen Sancho López de Ron e sus parientes e omes e criados e apaniaguados, le ferirán, o matarán, o lisiarán, o prenderán, a él e a sus procuradores e soliçitado- res e omes e criados e apaniaguados, o les tomará e ocupará sus bienes o alguna cosa de lo suyo ${ }^{52}$.}

Sin más noticias de Lope Núñez de Ron el viejo, desconocemos también cuándo muere su primogénito Alvar Díaz. Su hermano Sancho López de Ron, casado con una heredera de parte del señorío de Ibias, quedó finalmente instalado en la marina lucense donde por un segundo matrimonio emparentó con otro destacado capitán irmandiño, Alonso de Lanzós. Mientras, la rama de Alvar Díaz continúa en Asturias, y las siguientes noticias de la familia son, ya bien entrado el quinientos, de su hijo, también Lope Núñez de Ron, quien habrá de fundar su mayorazgo. Lo hará mientras replica los comportamientos ya habituales, fiel al ejemplo de su abuelo. Aún habrían de pasar muchos años para que el territorio se pacificase como glosaba el obispo Aponte de Quiñones, y de momento, como bien resumía una provisión real sobre Castropol, imperaba la ley de los malfechores.

\section{SEÑORAS DE VASALLOS}

La rama asturiana de los Ron vuelve a comparecer netamente en la documentación como la más significada de la Tierra de Castropol en la segunda década del quinientos, de la mano como ya se ha apuntado de un Lope Núñez de Ron continuador de su abuelo homónimo. De él y de su casa puede saberse fundamentalmente por diversas causas judiciales y varias disposiciones testamentarias.

Las primeras abundan, y son recurrentes en mostrarlo acusado por continuos altercados de los que se desprende un perfil de malfechor, al viejo uso que se ha

52. 1499, febrero, 28, Coruña. AGS, RGS, LEG, 149902, 149. Sabemos del mismo dos décadas después en iguales circunstancias, denunciado junto a un Ribadeneira por un canónigo de Mondoñedo. Vid. Saavedra, P. 1985: 45. Vasco de Aponte resulta equívoco en sus referencias al parentesco de los Ron, dando en un pasaje a Lope como hermano de Sancho y en otro a Alvar como padre de ambos. Nos inclinamos a seguir la genealogía que establecen los hermanos García Carraffa 1963, vol. 78, pp. 56-64. Muy probablemente siguen a Ron 1932. 
descrito para los tiempos de su abuelo, con desafío de diversas jurisdicciones y una frenética y reincidente actividad delictiva por todo el territorio asturgaláico. Aunque con esos datos no puede pasar de mera conjetura encontrar los motivos, quizá no hubiese otros que los ya apuntados más atrás, derivados de la necesidad de sostener un estatus ya cuestionable y el contingente de hombres de armas necesario para imponer su voluntad y hacerse valer ${ }^{53}$. Las algaradas tuvieron también, como se verá, su parte de exhibición de la capacidad de convocatoria - de apellidar- de un linaje, lo que necesariamente habría de tener su traducción en fuerza política.

La primera noticia que conocemos lo muestra en 1517, cuando irrumpió con sus hombres en un juicio en la Pola de Grandas ordenando matar al alcalde, Miguel de Cabrera, a quien dieron por muerto tras apalearlo. La acusación del fiscal alude a que desde años atrás venía cometiendo muchos y graves delitos, violentando muchos vasallos de la Corona, acogiendo y haciéndose acompañar de asesinos -omizianos - con los que robaba y mataba. Fue por ello condenado a una multa de 50.000 maravedís, al destierro a cinco leguas de la corte y por diez años fuera del Principado ${ }^{54}$, penas que, en el caso de los destierros, es seguro le fueron conmutadas, aunque no conste el auto.

Poco después ya debía de estar casado con Aldonza Rodríguez de Ibias y Quirós, descendiente por su padre, Gonzalo Bernaldo de Quirós, del importante linaje que ya hemos señalado como predominante en el centro de Asturias.

Cabe aquí reparar en la trascendencia de la política matrimonial de la casa, y en la significación de las mujeres en su paulatino engrandecimiento ${ }^{55}$. Pese a lo parco de las informaciones puede considerarse que los saltos verdaderamente cualitativos del rango familiar se vinculan al matrimonio. Si el enlace de Lope Núñez “el viejo" con Mayor de Miranda, la hija de Pedro el cruel, los situó en el entorno del mariscal Pardo de Cela, el de su primogénito Álvaro con Sancha de Parga lo hizo con otro significado linaje $\mathrm{e}^{56}$ mientras el hermano Sancho celebra tres matrimonios ventajosos, y ya se ha dicho cómo los Quirós de Aldonza encabezan la nobleza asturiana iniciado el siglo XVI. En fin, el último Álvaro Díez de Ron y Quirós se casará con Elvira de Cienfuegos emparentando con la pujante casa de Cienfuegos, señores del extenso concejo vecino de Allande que alcanzarán en el siglo XVII el condado de Marcel de Peñalba.

53. Al igual que Solórzano Telechea 2002, p. 53, definimos la situación con la frase de Achón Insáusti 1995, p. 71: "el dominio sobre los hombres, ya fuese por vía de parentesco o de pseudoparentesco (vasallaje, encomienda, tregua) es lo que otorgaba consentimiento de influencias sobre un territorio".

54. ARChV.; Registro de ejecutorias, caja 343,36.

55. Práctica bien conocida, es una constante en la familia. En un entorno muy similar lo ha estudiado con detalle Solórzano Telechea 2002, pp. 403 y ss.

56. La memoria genealógica elaborada por un descendiente atribuye a Sancha de Parga el señorío de Mohías y Folgueras, en el actual concejo de Coaña, sin que nos conste al respecto señorío alguno y sólo pueda relacionarse con las propiedades de los Navia en Coaña. Cf. Ron, 1932. El propio mayorazgo de Lope Núñez no hace referencia a tal señorío, como cabría esperar, y sí a "todos los vienes y hazienda que yo he y tengo y heredé por fin y muerte de doña Sancha de Párraga mi señora madre", ARChV, Registro de ejecutorias, caja 1330,69. 
Volviendo a la figura de Aldonza Rodríguez de Ibias, y remontando la genealogía hasta donde lo permiten con seguridad las fuentes, encontramos en el último tercio del siglo XV a tres hermanas como herederas del extenso señorío de Ibias: Emilia, María y Berenguela. Sus matrimonios fragmentarán el señorío en tres ramas llamadas a perpetuarse enlazándose entre sí repetidas veces, como muy expresivamente muestra el árbol genealógico que algún descendiente trazó en 1698 y que hoy se conserva ${ }^{57}$.

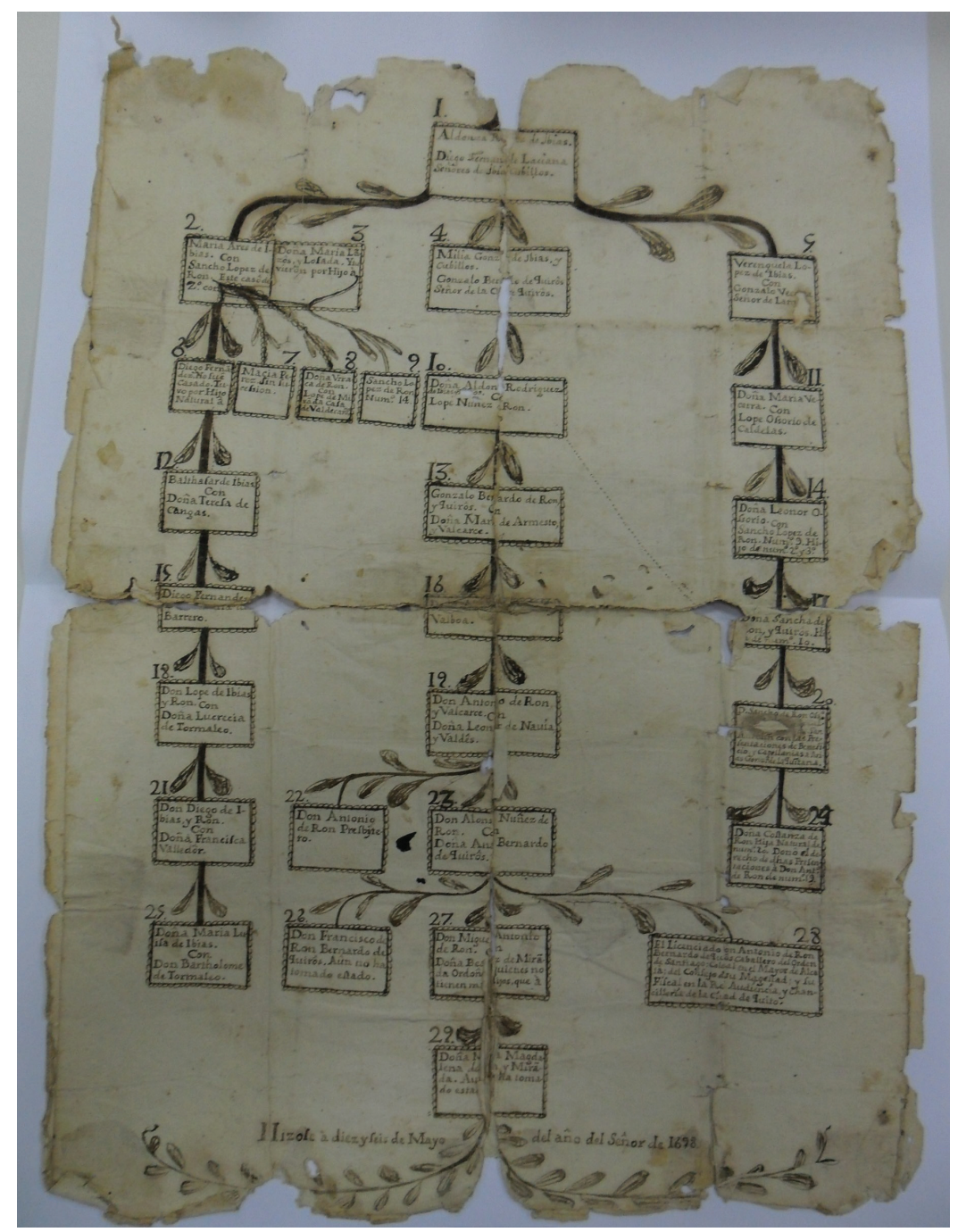

Fig. 3: Árbol genealógico de la casa de Ibias (a. 1698). Fotografía cortesía del AHA.

57. AHA, caja 199.218-12. 
Las circunstancias de la herencia sin duda resultaron atractivas para los caballeros más pujantes del momento, pues las tres añadían a una cuantiosa dote algo muy conveniente a los segundones de algunas familias: el señorío jurisdiccional sobre diversos lugares, paso importante en el ennoblecimiento. Emilia González de Ibias, señora de Cecos y Marentes, se casó con Gonzalo Bernaldo de Quirós; María Ares de Ibias lo hizo con Sancho López de Ron, el ya referido segundo hijo de Lope Núñez de Ron el viejo, aportando los señoríos de San Antolín, Tormaleo y Sena; y Berenguela de Ibias, heredera de Cubillos y Laciana, se casó en Galicia con Gonzalo de Becerra y Lamas.

De resultas, la familia de Ibias se reforzó en su entorno mediante el enlace con los Ron, y amplió geográficamente su ámbito de influencia a la Asturias central emparentando con la pujante casa de Quirós y al oriente gallego con los Becerra y Lamas. Al cabo de dos generaciones la casa de Ron acabará entroncando con las dos ramas paralelas hasta resultar preponderante en el concejo.

De los dos hijos de Gonzalo y Emilia, el varón, Iván Bernardo de Quirós, se casó con María Enríquez y no tuvieron descendencia, y su hermana, Aldonza Rodríguez de Ibias y Quirós, se casó con el primogénito de los Ron, Lope Núñez de Ron, asentándose ambos en Pesoz. En 1519 obtienen la licencia real para el mayorazgo, y por más que la retórica de las fórmulas notariales se repita en gran medida, sorprende ver la consideración que el rey expresa de los buenos e leales serviçios que vosotros y los dichos vuestros hijos nos avéis hecho, y esperamos nos aréis de aqui adelante ${ }^{58}$. En enero de ese mismo año, una real provisión ordenando al corregidor de Ponferrada que castigue a los delincuentes escondidos en Ibias dejaba ver expresamente la magnitud del desorden social en toda la montaña asturgalaica y la debilidad de los titulares de las jurisdicciones, y acaso con ello y con una intervención en el señorío de su madre haya que relacionar esa gratitud expresa:

\begin{abstract}
Sepades que por parte del Conde de Altamira y del Reverendo yn Christo Padre obispo de Astorga nos fue fecha relaçión que çerca de la tierra de Naba e Burón, que diz ques del dicho Conde, esta una tierra que diz que se llama de Ybias, e que a cabsa de ser de jurediçiones diversas y porque la dicha tierra de Ybias diz ques de tres personas, e que las dos diz que son mujeres viudas, se acojen a la dicha tierra muchos delinquentes e malechores y encartados que se van hullendo del Reyno de Galiçia. Y otras personas diz que toman atrebemiento de hazer e cometer otros delitos creyendo e teniendo por çierto que se han de baler en la dicha tierra. E que si lo susodicho no se remediase sería dar ocasión a que se syguiesen muchas muertes y escándalos. E nos fue suplicado e pedido por merçed vos mandásemos que castigásedes a los dichos malhechores, o como la nuestra merçed fuese $e^{59}$.
\end{abstract}

Por fin, el 21 de agosto de 1521, y muy significativamente pocos días después de la muerte de Emilia, la titular de los señoríos de Cecos y Marentes que serían el orgullo del mayorazgo de los Ron de Pesoz, Lope Núñez y Aldonza Rodríguez

58. ARChV., Registro de ejecutorias, caja 1661-0024.

59. García Oro y Portela Silva 2003, pp. 651-653. 
fundaron vínculo de mayorazgo señalando como heredero a su primogénito, Alvar Díez de Ron y Quirós ${ }^{60}$.

Aunque ennoblecido por el modesto señorío de vasallos, el comportamiento depredador característico seguirá mostrándose constante. Unos años después, en un pleito muy prolijo, en el que se acumulan las acusaciones del juez de Castropol y las del fiscal de la corte ${ }^{61}$, nuevamente encontramos un aire de familia en la osadía de un Lope Núñez de Ron acompañado de hasta doscientos hombres después de "apellidar la tierra" para convocar partidarios y campar por la comarca desafiando jurisdicciones eclesiásticas -la episcopal de Castropol y Grandas o el abadengo de Villanueva de Oscos-. Algunos fragmentos de esta causa resultan bastante elocuentes sobre el patrón de conducta, y el relato de sus algaradas en nada se distingue del de un bandolero:

[...] en el mes de agosto del año pasado de quinientos e veynte e tres se fue a la pola de Grandas con fasta veyn[te on]bres [...] e ausentados de la justiçia e con gran alboroto y escándalo por fuerça y con mano armada tomó e levó quatro o çinco carros de pan de unas medas de Pedro de As Lojas que llevaba de un casal del dicho Hernando de Mon; y la dicha meda de pan çierta parte della hera del dicho casal, y lo majó e hizo dello lo que quiso. Y porquel dicho Hernando de Mon vino a requerirle que le diese el dicho su pan e no le hiziese la dicha fuerça, adreçó a él e le yrió con una vallesta dos o tres paletadas, e lo oviera de matar a él e a otros que benían con él con fabor e ayuda de los dichos encartados malfechores.

Asimismo, después de aver fecho la dicha fuerça, el dicho Lope Núñez hizo apellidar la tierra e repicar las campanas, en que ayuntó e combocó más de dozientos onbres, e se hizo fuerte con ellos en la su casa de Pesoz para se defender de la justiçia y ofenderla. [...] trayendo en presençia del dicho alcalde e juez los dichos omeçidos e mal fechos en su desacatamiento, y con ellos e con la gente que traýa se yba y se recogía a la dicha su casa de Pesoz e con ellos andava alborotando en el dicho conçejo de Grandas ollando y comiendo a costa de los vezinos dél, e aún tomavan a los dichos vezinos algunas cosas de sus casas syn su liçençia, e con ellos andavan amenazando[... $]^{62}$.

Si algunos testimonios son bien elocuentes de la participación del propio Lope en las luchas ${ }^{63}$, no falta tampoco en esas banderías la de Aldonza Rodríguez, todo un carácter volcado con vehemencia en la política familiar al uso de los Quirós, la

60. ARChV., Registro de ejecutorias, caja 1661-0024. De la importancia del señorío de vasallos como factor de distinción entre una hidalguía generalizada da muestra el que Lope Núñez de Ron consigne en su escritura en 1554 de mayorazgo una fuerte suma por "si se vendieren vasallos de iglesias o de monesterios o de otra qualquiera persona" para invertirlos "en la compra de los tales vasallos y en la renta y derechos y jurisdiciones que con ellos se vendieren”. Un afán en el que porfiarán sus herederos cuando los concejos de la obispalía se subasten.

61. La ejecutoria está fechada el 20 de abril de 1527. ARChV., Registro de ejecutorias, caja 397,50 .

62. ARChV., Registro de ejecutorias, caja 397,50.

63. Ibidem. En otra declaración en el mismo pleito se lee: "E porque Hernando de Mon lo avía querido defender, el dicho Lope Núñez avía puesto en obra de lo matar, tirándole con una vallesta muchas saetadas, $[\ldots]$ ".. 
familia de su padre. El fiscal la denuncia por desacato, señalando cómo, al serle notificada la carta de amparo real sobre su adversario Fernando de Mon y su gente, respondió airada que "más valían unas coraças que la dicha carta e seguro", y que fue ella misma, un mes después, quien estando en la vendimia con algunos de sus criados ordenó matar a Hernando de Jarrio, pariente de los Mon ${ }^{64}$.

Huidos de la justicia algunos de sus hombres y acogidos al asilo de la iglesia de Castropol $^{65}$ la algarada -no carente de provocación, nótese cómo se corea el nombre de la casa- fue extendiéndose a todas las jurisdicciones del entorno, de las pueblas de Grandas y Castropol a Galicia y de allí al abadengo de Villanueva de Oscos:

"e aviendo por bueno el dicho delito e heridas que cometyeron los dichos Françisco e Pero Hernández, e vino a entender > el dicho Lope Núñez< en negoçiar cómo fuesen sueltos de la cárçel del dicho obispo, donde estaban presos, trayendo consygo treynta onbres armados; con fabor de los quales y por mandado del dicho Lope Núñez un su criado que se llama Alonso Arias, que con él andaba, soltó e ayudó a soltar a los dichos Pero Hernández e Françisco de la fortaleza de Castropol, donde estavan presos, e los aconpañó hasta los meter en la yglesia de Sant Martín de Campo con una vallesta armada, dando bozes e apellido "Ron, Ron", estando el dicho Lope Núñez çerca dellos con la dicha gente alborotada, determinando de los tomar e reçebtar e resystir a la justiçia. E ansy lo posiera por obra sy no se metyera en la dicha yglesia.

E después, estando çercados y teniendo velas el dicho alcalde mayor, como los susodichos Françisco e Pero Hernández, que avían quebrantado e hudo de la cárçel, no se fuesen ni saliesen de dicha yglesia sin ser presos fuera della, el dicho Lope Núñez se pasó de la villa de Ribadeo, donde estuvo con fasta treynta onbres armados de diversas armas e algunos encartados [por] homeçidas e malhechores, se fue a la [dicha] yglesia e sacó e ...çercó della a los [suso]dichos Pero Hernández e Françisco Pataguín ${ }^{4 r}$ reziándolos y llevándolos consygo fasta meterlos como los metió en la ribera de la dicha villa de Castropol, e de alli en un varco los pasó a Ribadeo con çiertos onbres de los que con él yban. E puesto quel dicho alcalde mayor le mandó so çiertas penas que no se partiese de la dicha villa sin su liçençia e mandamiento hasta questo biese la justiçia, se fue e ausentó en quebrantamiento

64. El linaje de los Mon tiene su origen en una rama secundaria de los Ron emergente en el mismo contexto que tiene su asiento en la aldea de Mon, situada muy cerca de Pesoz. El fundador del mayorazgo, Fernando de Mon, coetáneo de Lope Núñez de Ron, establece su mayorazgo en 1551. Con el tiempo los Mon alcanzarán el predominio en el espacio eonaviego de montaña y en el tránsito del siglo XVIII al XIX alcanzan las posiciones más elevadas del reino. Cf. Álvarez Castrillón, 2013.

65. El quebrantamiento de prisiones, habitualmente complicado con el asilo en sagrado, era delito muy habitual y una de las cuestiones que el Estado moderno debió perseguir con más firmeza para imponer la supremacía del aparato público de justicia. Al respecto véase Ramos Álvarez 2008, pp. 223-231. En este caso la jurisdicción episcopal de Castropol estaba obligada a respetar el asilo en la iglesia de Santa María de Campo, prerrogativa que defendía la Iglesia en otras jurisdicciones. En otra declaración, esta de 1537 sobre un suceso en Villarpedre, sorprende cierto aire casi cotidiano cuando el testigo da cuenta de "Alonso de Mesa, clérigo e cura del dicho lugar, cómo avía mandado al dicho Diego Cadenas que abriese la puerta de la dicha yglesia e que se fuese al monte porque no le prendiese la justiçia", e invita a reparar en el controvertido papel del clero. ARChV. Sala de Hijosdalgo, caja $0306.0021,49 \mathrm{r}^{\mathrm{o}}$. 
del dicho mandamiento e carcelería [...] Y que con los dichos malhechores el dicho Lope Núñez avía puesto en obra de matar a çiertos vezinos del coto de Villanueva. [...] por mandado del dicho Lope Núñez se fueran al conçejo de Grandas, donde el dicho Lope Núñez vive, e alli amparedaron a Arias Verjano, criado de Arias de Mon, e le dieran de cuchilladas e palos e lançadas. " 66

En la resolución de tan graves cargos se dejará ver la debilidad de los poderes públicos y la dificultad de afrontar los desafíos de algunos caballeros a la autoridad. Aldonza Rodríguez, presa y sentenciada a destierro por diez años, abonó la fianza y tras el recurso en Valladolid quedó en libertad. En cuanto a Lope Núñez, en primera instancia la sentencia del alcalde mayor en el partido de Castropol y Grandas por el obispo fue severísima, ordenando el derrocamiento de la torre de Pesoz, el escarnio público y el ajusticiamiento:

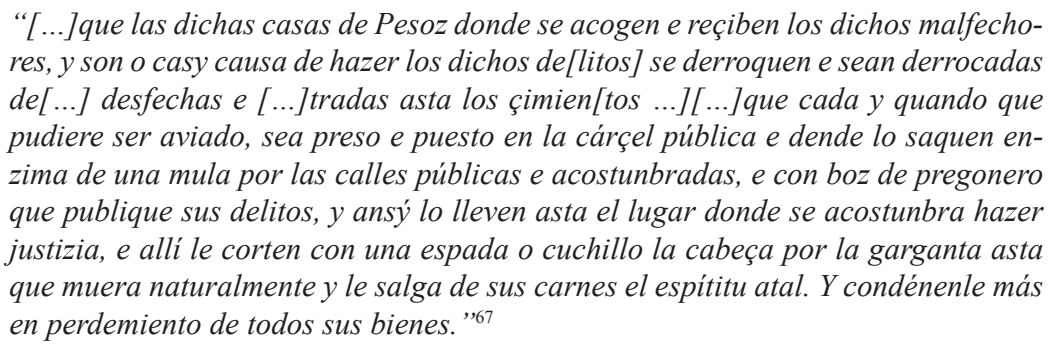

No obstante, por apelaciones sucesivas ante la Chancillería de Valladolid, la sentencia será revocada y finalmente se rebajará la pena a dos meses de destierro y al pago de las costas del proceso, trasmitiendo una vez más una evidente impunidad.

Unos años después, en 1535, en el elocuente encabezado de un pleito encontramos una imagen insólita pocos años antes:

"En el lugar de Pesoz que es en el concejo de Grandas, a siete días de mes de otubre de mil e quinientos e treynta e çinco anos, en presencia de mí el escrivano e testigos de yuso escritos, estando presentes el magnífico señor Lope Núñez de Ron como justicia del coto de Villanueva d'Oscos e Sancho da Braña, juez del concejo de Grandas, ... " ${ }_{68}$

Conocido motivo de disputa y ansiado beneficio de la nobleza, el acceso a los oficios de la jurisdicción parece haber contribuido a la pacificación del territorio.

66. ARChV., Registro de ejecutorias, caja 397,50.

67. Ibidem.

68. ARChV., Sala de hijosdalgo, caja 0306.0021. 


\section{6.- El MAYORAZGO}

Mediado ya el siglo, son los dos testamentos de Lope Núñez de Ron la referencia esencial sobre la familia. En 1554 Lope Núñez amplía en beneficio de Alvar Díez el vínculo que otorgara en 1521 junto a su ya difunta mujer, para revocarlo dos años después instituyendo como heredero a Gonzalo Bernaldo de Quirós. Las diferencias entre estos abren una serie de pleitos que duran al menos veinte años y de los que resultan dos mayorazgos paralelos. Alvar mantiene el otorgado por su madre, y Gonzalo se beneficia del último de su padre ${ }^{69}$.

Una breve reseña del vínculo establecido en 1554 deja ver, además de un importante incremento patrimonial con respecto al relacionado en 1521 y una amplia distribución por la confluencia asturgalaica ${ }^{70}$, algunas señales de la transformación paulatina de intereses y conductas familiares: su proyección en la corte con una residencia fija, la dote para estudios de los segundones ${ }^{71}$, y una mayor diversificación económica:

las casas $y$ torres y bodegas, heredades y viñas y casares de pan y bino y renta y diezmos, lutuosas y branas y montes, prados, pastos, bravos y mansos, presas y molinos, poços de ríos, fueros y derechos que yo he y tengo y me pertenezcan y puedan pertenezer en qualquier manera y por qualquiera título y causa en los conzejos de Castropol y Grandas e Ybias y Miranda y conçejo y valle de Lorençana y en el conzejo de Burón y en el conzejo de Navia de Luarca y Navia de Suarna y del conzejo de Allende e todo el coto de Marentes, y basallos y bienes dél, e más todos los vasallos y bienes y renta que yo tengo en los cotos de Recesende de a Villaseca y la ferrería de Villaseca y el juro que yo he comprado de su magestad y çensos, así perpetuos como al quitar que yo compré así en el concejo de Ybias como en otros qualesquiera partes y toda qualquiera jurisdicción cebil y criminal que yo he y tengo, con más todos los derechos de patronazgo y presentación que yo tengo en qualquiera yglesia e todos qualesquiera dezmos y rentas de yglesia que a mí me pertenezcan en qualquier manera (...) e más las casas e palomar y ribera que yo compré en la villa de Valladolid en su arrabal, e la duela y botas y madera que yo tengo en la vega de Ribadeo e me sea debido en qualquiera manera, e todos los fueros de hórdenes e yglesias e monesterios que yo tengo y me pertenezca en qualquiera manera e sin esenziones, (...) el conde de Salinas me debe y es a cargo tres mil ducados que de mí recibió en dineros (...) y más le r $^{\circ}$ doy todas las bacas y yeguas y ganado mayor que yo he y tengo en los dichos conzejos y cotos y branas dellos y en comunidad y en poder de qualesquier personas $(. . .)^{72}$.

69. La ejecutoria del pleito entre Álvaro Díez de Ron y su hermano Gonzalo Bernardo de Ron, con los dos mayorazgos, en ARChV., Registro de ejecutorias, caja 1125,30.

70. Las propiedades relacionadas en el vínculo establecido en 1521, evidencian un carácter agrario, salvo "La casa de Pesoz en que agora vivimos", la jurisdicción de Ibias, "la media parte de la ferrería de Vila Seca y coto de Recesende" y "la mitad de las ferrerías de Suero e de Montealegre según como las compramos al m[arqués de] Astorga." ARChV., Registro de ejecutorias, caja 1661-0024.

71. "Otrosí, quiero y es mi voluntad que los susçesores desta mi casa e mayorazgo, teniendo hermanos legítimos segundos sean obligados a darles alimentos en la universidad de Salamanca si quieren estudiar."Ibidem.

72. ARChV., Registro de ejecutorias, caja 1330,69-8. 
Señalaba hace algunos años Díaz de Durana el interés de indagar sobre los ingresos de la pequeña nobleza para determinar su fundamento económico y cabe decir que el análisis sobre el linaje que nos ocupa satisface una por una sus hipótesis $^{73}$. Obviada ya la rentabilidad de la milicia en tiempo de paz, el detalle de las propiedades señala una base bien diversificada: la agricultura, con especial relevancia del viñedo, la aparcería de abundante ganado por las brañas, pero también la industria presente en una bodega en Vegadeo y la duela acumulada, que denota una eminente vocación comercial, y una proporción muy importante de ferrerías. El préstamo de dinero que se menciona, los juros, censos y las rentas diezmales y derechos de presentación completan el exhaustivo panorama de activos e intereses.

Por otro lado, la relación de la descendencia de Lope Núñez de Ron y Aldonza Rodríguez de Ibias y Quirós permite constatar, entre otras cosas, cómo los belicosos antepasados Pedro de Miranda o Gonzalo Bernaldo de Quirós son aún una referencia esencial en la familia. ${ }^{74}$ Así constan, además del primogénito Alvar Díez, doña Mayor y doña María, monjas profesas en el monasterio zamorano de Santa Clara de Villalobos - señorío de los Osorio- ${ }^{75}$, Pedro de Miranda, Sancha de Ron, Milia de Ron, Gonzalo Bernaldo de Quirós, además del reconocimiento de otros dos hijos naturales de Lope, Hernán González de Ron y Constanza Vázquez de Ron $^{76}$.

Fallecido Lope en fecha que desconocemos, se advierte que quien disfruta el vínculo mientras se resuelven los pleitos es Alvar, al menos en Pesoz, la residencia principal del linaje, y es allí donde en 1564 se desarrollan los acontecimientos que alimentarán la leyenda y que reseñábamos al inicio del trabajo.

Los denunciantes, el padre y el hijo del sacerdote - menor representado por un curador legal- y un tercero, sin duda familiar, acusan a Álvaro Díez de Ron y a su entorno de criados y parientes del asesinato, por rencillas anteriores y aludiendo a la venganza por diferencias en negocios. En la elocuencia de una denuncia encontramos un perfil del acusado coincidente con lo que más arriba describíamos como malfechor:

73. Díaz de Durana 2004, p. 83. En 159 y siguientes señala cómo las ferrerías son una parte esencial de la economía señorial. Solórzano Telechea 2005, p. 162, señala también como base de su preeminencia el comercio, la guerra, la propiedad rural y urbana y los beneficios de la actividad ferrona.

74. Se acerca a la figura de Gonzalo Bernardo de Quirós, en el contexto de su tío bastardo del mismo nombre, González Calle 2007b.

75. El monasterio de Santa Clara de Ribadeo, con el que ya los Miranda tenían relación como foreros -Mayor, la mujer de Lope Núñez de Ron, renueva un foro en 1483, después de ajusticiado su padre Pedro el Cruel-, acoge durante el siglo XVI a diversas monjas de la familia Ron. Así consta mencionada en sus fuentes varias veces entre 1559 y 1603 doña Leonor de Ron, por cuya legítima y dote el monasterio cobraba tres tegas de centeno en los Oscos, en los lugares de Ron, Santalla y San Martín; también es mencionada en 1586 doña Inés López de Ron y, ese mismo año y en 1599 María Álvarez de Ron. Cf. De Castro y De la Cruz 1988, pp. 36, 38, 117 y 127.

76. Esta última casada con Diego Suárez en Prelo (Boal), uno de los lugares donde tendrá continuidad la leyenda derivada del asesinato 1554, enero, 23. ARChV., Registro de ejecutorias, caja 1330,69 . 
el dicho Álvaro Díez hera en la dicha tierra caballero poderoso y rico, las justiçias nunca se abian atrevido ni abian sido poderosas para le prender y castigar y no enbargante que sabía y le hera notorio que el dicho Álvaro Díez antes que matase al dicho Alonso Cuerbo abía hecho otros muchos grandes delitos y muertes ${ }^{77}$.

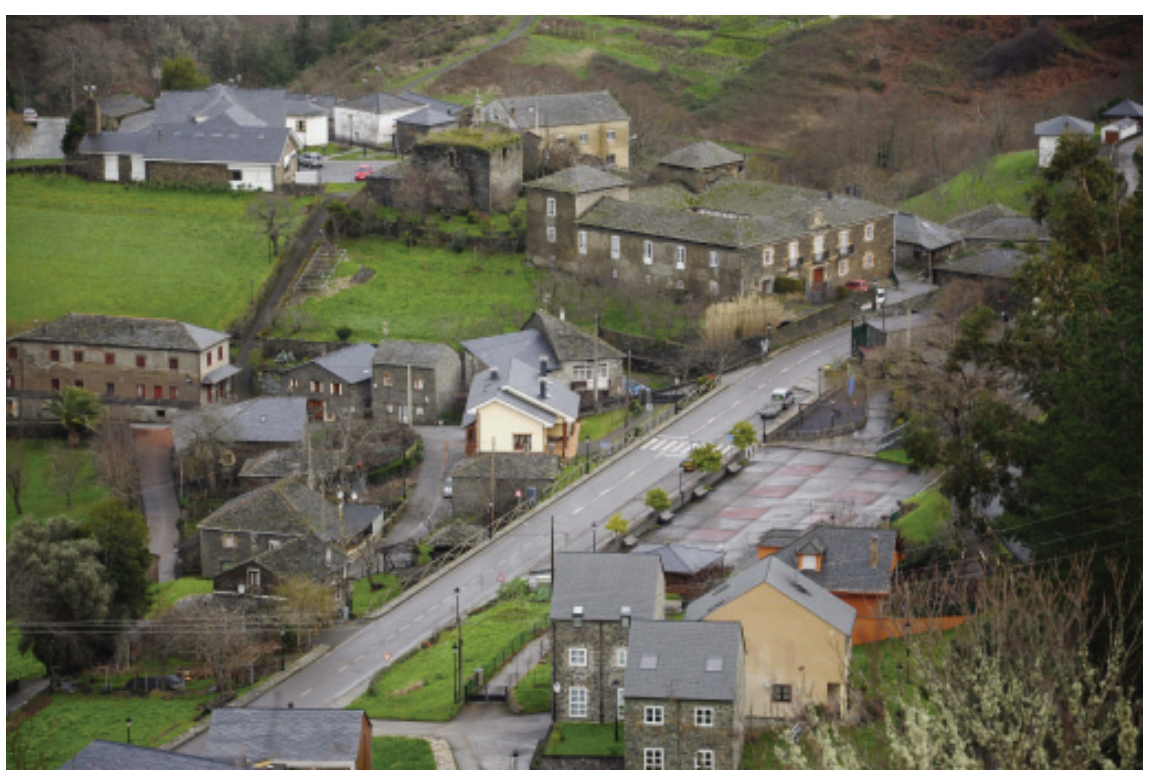

Fig. 4: Panorámica de la villa de Pesoz. En el centro destaca el hoy remozado palacio que fue de los Ron, y en su parte trasera la torre medieval. Fotografía: Salvador Rodríguez Ambres.

A partir de entonces se inicia un proceso que sucesivas apelaciones alargarán en la Chancillería de Valladolid una década, coincidiendo siempre las sentencias en la culpabilidad del reo aunque también en suavizar la pena a medida que el acusado vaya desplegando su influencia e incluso compre algún perdón o la retirada de la acusación, entre ellos los del padre de la víctima y el del curador del hijo ${ }^{78}$. Así, evolucionará de la vergüenza y ejecución pública, y el derrumbe de la casa torre familiar con compensación económica al huérfano de la primera sentencia, al destierro por unos años, que si inicialmente le obligaba a servir en la frontera africana quedó en cuatro fuera del reino y seis más del Principado y la corte, decretado el 6 de noviembre de 1574 .

Fallecido en fecha que desconocemos, la sucesión de Álvar Díaz recayó en una hija, Antonia de Ron, que casó con Álvaro Pérez de Navia y Bolaño y falleció sin descendencia. Después de ella heredó el mayorazgo su primo Antonio de Ron y

77. ARChV, Registro de ejecutorias, caja 1304,13

78. Así constará en pleito posterior que Juan García de Tineo, pariente dentro del cuarto grado y curador del menor, le vendió un perdón por 400 ducados. Cf. ARChV, Registro de ejecutorias, 1498, $4^{\mathrm{r}^{\circ}}$. 
Valcarce, nieto de Gonzalo Bernaldo de Ron y Quirós, y el linaje, por más que el heredero forzosamente portase el apellido de los Ron como estaba establecido en el vínculo, fue trasladando el protagonismo a otras familias y adaptando sus conductas a los nuevos tiempos. Los nuevos Ron de Pesoz destacarán durante el siglo siguiente como capitanes a guerra de los concejos de Grandas e Ibias.

\section{CONCLUSIONES}

El análisis de la trayectoria de los Ron desde que es posible documentarlos con continuidad a principios del siglo XV, permite trazar el proceso de su ascenso desde el estatus de escuderos de rango local a la cabeza de la pequeña nobleza característica del extremo occidental de Asturias. Iniciados al servicio de los Osorio ya en el siglo anterior durante las turbulencias trastamaristas, la hidalguía local tendrá oportunidad continuando ese vasallaje de asentarse como su autoridad delegada en la extensa encomienda episcopal de la Tierra de Castropol. La sostenida inestabilidad política del siglo XV convierte la situación en endémica a medida que generación tras generación el acoso y la tutela de las jurisdicciones y propiedades eclesiásticas se consolida como fuente de ingresos y poder.

En esa coyuntura, cada uno de los frecuentes episodios bélicos -luchas entre la nobleza gallega, las revueltas irmandiñas, la guerra de Granada o contra Portugal-suponen una oportunidad de aumentar el prestigio de cuyo beneficio por parte de los Ron no dejan duda los ventajosos matrimonios que celebran estableciendo alianzas con otros pujantes linajes que mejoran su rango. De ese modo, al final de la centuria se codean con la abundante nueva nobleza gallega.

Con el reinado de los Reyes Católicos y su política de reforzamiento del Estado la secuencia de demandas de las jurisdicciones eclesiásticas -el monasterio de Villanueva de Oscos o las pueblas de Castropol y Grandas- muestra un esfuerzo sostenido del poder público por revertir la situación. En esa lucha los Ron asoman a la documentación constantemente encabezando una revoltosa nobleza local que se resiste a perder sus hábitos y muestra una connivencia habitual con bandas de merodeadores a las que con frecuencia parecen asimilarse. Iniciado el siglo XVI y carente de sentido ya la encomienda, el acoso a las jurisdicciones y a los vecinos que no les son afectos se muestra como un medio de presión que sólo parece haberse resuelto con una decidida acción de la corona y con el acceso de los hidalgos al ejercicio de algún oficio de justicia. Es el caso de los Ron en Pesoz o en el coto de abadengo de Villanueva.

Señal de los nuevos tiempos, y aunque se advierte una querencia por los usos violentos que perdurará hasta resultar anacrónica bien rebasada la mitad del siglo XVI, otros indicadores denotan la adaptación de la estrategia familiar a las nuevas estructuras: la institución del mayorazgo, la proyección en la corte, incluso con residencia permanente, la orientación al estudio de algunos hijos, o la paulatina diversificación de rentas, que trasciende el clásico interés agro-ganadero para abarcar ya la industria, el comercio, las finanzas o los derechos y beneficios ecle- 
siásticos. En este sentido resulta significativa la consignación prioritaria para la compra de jurisdicciones frente a la inversión ganadera.

\section{BIBLIOGRAFÍA}

Acevedo y Huelves, B. (1898). Boal y su concejo, Oviedo, tipografía de Adolfo Brid.

Achón Insausti, José Ángel. (1995). “A voz de concejo”. Linaje y corporación urbana en la constitución de la Provincia de Gipuzkoa. San Sebastián.

Álvarez Castrillón, José Antonio (2001). Los Oscos en los siglos X-XIII. Un modelo de organización social del espacio en la Asturias medieval. Oviedo

Álvarez Castrillón, José Antonio (2007). La comarca de los Oscos en la Edad Media, poblamiento, economía y poder, Oviedo, KRK.

Álvarez Castrillón, José Antonio (2011). Colección diplomática del monasterio de Santa María de Villanueva de Oscos, Oviedo, Real Instituto de Estudios Asturianos.

Álvarez Castrillón, José Antonio (2013). El ambiente de la Ilustración en el occidente de Asturias. Trazas y semblanzas, Oviedo, Real Instituto de Estudios Asturianos.

Barros Guimerans, Carlos (1988). A mentalidade xusticieira dos irmandiños, Vigo.

Barros Guimerans, Carlos (2008). "La guerra de los caballeros en la Galicia medieval" Norba. Revista de historia, Universidad de Extremadura, vol. 21: 205212.

Calleja Puerta, Miguel, (2005). "La Asturias Medieval”, en Historia de Asturias, KRK, Oviedo, pp. 286-287.

Calleja Puerta, Miguel, (2010). "El factor genealógico: posibilidades y límites de la documentación de archivo para la elaboración de historias familiares". Emblemata, 16, pp. 123-153.

Cuartas Rivero, Margarita (1975). "Los corregidores de Asturias en la época de los Reyes Católicos", Asturiensia medievalia, n 2, págs. 259-278.

Dacosta, Arsenio, (2003). Los linajes de Bizkaia en la Baja Edad Media. Poder, parentesco y conflicto, Bilbao.

De Carvallo, Luis Alfonso (1695). Antigüedades y cosas memorables del Principado de Asturias, edición de Silverio Cañada. Oviedo, 1988.

De Castro, Manuel, OFM, y de la Cruz, María Ángeles, OSC. (1988). El monasterio de Santa Clara de Ribadeo. Historia y edición documental. El Ferrol.

Díaz de Durana Ortiz de Urbina, José Ramón (2004). La otra nobleza. Escuderos e hidalgos sin nombre y sin historia. Hidalgos e hidalguía universal en el País Vasco al final de la Edad Media, Universidad del País Vasco, Bilbao.

Fernández Suárez, Jesús (2014). “Entrambasauguas”. La marina occidental asturiana en la plena Edad Media, Departamento de Historia, Facultad de Filosofía y Letras, Universidad de Oviedo (tesis doctoral, en prensa). 
Fernández Suárez, Jesús (2015). De Entrambasauguas a la Pobla de Castropol. El tiempo de don Gonzalo Menéndez, Castropol, KRK ediciones.

García Carraffa, Antonio y García Carraffa, Alberto (1963). Diccionario Heráldico y Genealógico de Apellidos Españoles y Americanos, Vol. 78.

García Oro, José (1981). La nobleza gallega en la Baja Edad Media, Santiago de Compostela.

García Oro, José (1987). Galicia en los siglos XIV y XV, vol. 1, Pontevedra.

García Oro, José y Portela Silva, María José (2002). “Osorios, Bolaños, Pardos y Ribadeneiras: las casas nobles lucenses camino de la modernidad", en Anuario Brigantino, $\mathrm{n}^{\circ} 25$, pp. 151-180.

García Oro, José y Portela Silva, María José (2003). La casa de Altamira durante el Renacimiento, Estudio introductorio y colección diplomática, Santiago de Compostela.

González Calle, Jesús Antonio. (2007a) "Luchas de bandos en Asturias en la época de los Reyes Católicos" Isabel La Católica y su época: actas del Congreso Internacional, Valladolid-Barcelona-Granada, 2004 / coord. por Ribot García, L. A., Valdeón Baruque, J., Maza Zorrilla, E., Vol. 1, pp. 519-544.

González Calle, Jesús Antonio. (2007b). “¿Qué fue de Gonzalo Bernaldo de Quirós 'el Bastardo'?: el misterio de una sepultura en la Baja Edad media asturiana" Territorio, sociedad y poder: revista de estudios medievales, №. 2, pp. 275-296.

González Novalín, José Luis (1986). Las visitas “ad limina” de los obispos de Oviedo (1585-1901). Una fuente eclesiástica para la historia de Asturias, Oviedo, Real Instituto de Estudios Asturianos.

González Paz, Carlos Andrés (2004): “El castillo de Peñaflor (Riotorto-Lugo): Iglesia y nobleza en la mariña lucense a finales de la Edad Media", Boletín do Museo Provincial de Lugo, no. 11, 2, pp. 19-52.

Ladero Quesada, Miguel Angel (1996). "La consolidación de la nobleza en la Baja Edad Media”, en Nobleza y sociedad en la España Moderna, Iglesias, M ${ }^{\mathrm{a}}$ C., ed., Madrid, 1996, pp. 19-45.

Lence Santar y Guitián, E. (1930). El mariscal Pardo de Cela. La santa Hermandad. Mondoñedo, pp. 76, 77.

Lojo Piñeiro, F. (1991). A violencia na Galicia do século XV, Santiago de Compostela.

Martín Fuertes, José Antonio (1987). "Los Osorio y el marquesado de Astorga"; Tierras de León: Revista de la Diputación Provincial, Vol.27, n 66, pp. 35-46 .

Martín Fuertes, José Antonio (1988). De la nobleza leonesa. El marquesado de Astorga.

Meilán García, Antón Xosé (2006). “A orixe do desenvolvemento do mito de Pardo de Cela ata o século XX”, en $O$ mariscal Pardo de Cela e o seu tempo, AA.VV., Lugo, p. 224.

Pardo de Guevara y Valdés, Eduardo (2006). "El mariscal Pardo de Cela: leyenda, mito y realidad", en $O$ mariscal Pardo de Cela e o seu tempo, AA.VV., Lugo, p. 48. 
Pardo de Guevara y Valdés, Eduardo (2012). De linajes, parentelas y grupos de poder. Aportaciones a la historia social de la nobleza bajomedieval gallega, Madrid.

Pardo de Guevara y Valdés, Eduardo (2013). "El testamento del mariscal Pardo de Cela. Noticia del hallazgo y edición del documento", en Cuadernos de Estudios Gallegos, n 126, pp. 171-223.

Pérez de Castro, Ramona (1987). Los señoríos episcopales en Asturias. El régimen jurídico de la obispalía de Castropol, Oviedo, Real Instituto de Estudios Asturianos.

Ramos Álvarez, Isabel (2008). Arrestos, cárceles y prisiones en los derechos históricos españoles, Madrid.

Rodríguez Díaz, Elena (1995). El Libro de la Regla Colorada de la Catedral de Oviedo, Oviedo, RIDEA.

Ron, Antonio (1932). La casa de Ron y sus agregadas: Ibias, Quirós, Valcarce, Caballero y otras. Estudio genealógico y heráldico, Lugo.

Rubio Pérez. Laureano (2002). "El Estado y Marquesado de Astorga. Relaciones de poder, rentas y economía señorial, siglos XVII-XVIII"; La documentación para la investigación: homenaje a José Antonio Martín Fuertes, Tomo II, Universidad de León, pp. 83-116.

Rubio Martínez, Amparo (2012). "Los primeros vizcondes de Altamira en la villa de Viveiro: adquisición y pérdida de un señorío en el reino de Galicia" Cuadernos de Estudios Gallegos, LIX Núm. 125, pp. 95-114.

Ruiz de La Peña Solar, Juan Ignacio (2002), Prólogo a González Calle, Jesús Antonio, Los Escamprero y los Areces, escuderos de las Regueras. La pequeña nobleza rural asturiana en la Baja Edad Media. Oviedo.

Ruiz de La Peña Solar, Juan Ignacio (2005). "Realeza y concejos versus ladrones y malfechores: la lucha contra la delincuencia en la Asturias medieval (siglos XIII-XV)", Boletín de Letras del Real Instituto de Estudios Asturianos, n 166 , pp. 41-60.

Saavedra, Pegerto (1985). Economía, política y sociedad en Galicia: la provincia de Mondoñedo, 1480-1830, Madrid, Xunta de Galizia, Servicio central de Publicaciones.

Santo Tomás y Pumarada, fray Toribio (1714). Arte General de Grangerías, 2 vols., Salamanca, 2006.

Solórzano Telechea, Jesús Ángel, (2002). Santander en la Edad Media. Patrimonio, parentesco y poder. Santander.

Solórzano Telechea, Jesús Ángel, (2005). "Violencia y conflictividad política en el siglo XV: el delito al servicio de la élite en las cuatro villas de la costa de la mar", Anuario de Estudios Medievales, 35/1, pp. 159-184.

Suárez Álvarez, María Jesús, (1972). “Aportaciones asturianas a la guerra de Granada", Asturiensia Medievalia 1, Oviedo, pp. 307-356.

Uría Ríu, Juan (2010). “Contribución al estudio de la luchas civiles y el estado social de Asturias en la segunda mitad del siglo XV", en Obra completa IV, Estudios medievales, Oviedo, KRK: 265-303. 
Vasco de Aponte, (1986). Recuento de las casas antiguas del Reino de Galicia, Introducción y edición crítica a cargo del equipo de investigación "Galicia hasta el 1500" integrado por Manuel Díaz y Díaz et al., Santiago de Compostela, Consellería da Presidencia, Servicio Central de Publicacións, 1986.

Villa González, Palmira (1975). "Los corregidores de Asturias en la época de los Reyes Católicos”, Asturiensia medievalia 2, pp. 259-278.

Fecha de recepción del artículo: 21 de marzo de 2017

Fecha de aceptación y versión final: 9 de mayo de 2017 